\title{
La cultura popular española en las fotografías de Ruth Matilda Anderson. Representaciones del pasado y relecturas digitales
}

\author{
Spanish popular culture in the photographs of Ruth Matilda \\ Anderson: Representations of the past and digital reinterpretations
}

\author{
María Jesús Pena CASTRo \\ (Universidad de Salamanca USAL) \\ mpena@usal.es \\ ORCID: 0000-0003-1992-1259
}

\begin{abstract}
Ruth Matilda Anderson (18931983) was an American photographer who travelled from 1923 to 1967 to Spain employee by The Hispanic Society of America to document in more than 14000 pictures the rural society. This paper analyzes her work through her personal, artistic and research profile clearly defined by the principles of this institution and the image of Spain inspired by its founder Archer Milton Hungtinton. Contemporary readings of her legacy will also be evaluated as part of new reviews of popular culture in digital media.
\end{abstract}

KeYwords: Ruth Matilda Anderson, Visual Anthropology, Gender, Popular Culture, Identities.
Resumen: Ruth Matilda Anderson (18931983), fotógrafa estadounidense, documentó la vida rural española entre 1923 y 1967 en más de 14.000 imágenes por encargo de la Hispanic Society of América. Este artículo analiza su obra de a través de su perfil personal, artístico e investigador, claramente definido por los principios de esta institución y la imagen de España inspirada por su fundador Archer Milton Hungtinton. También se evaluarán las lecturas contemporáneas de su legado como parte de las nuevas revisiones de la cultura popular en los medios digitales.

Palabras-Clave: Ruth Matilda Anderson, Antropología visual, Género, Cultura Popular, Identidades.

En agosto de 2019 en el castillo de Santa Cruz de Oleiros (A Coruña) se celebró la exposición «Una mirada de antaño. Fotografías de Ruth Matilda Anderson en Galicia» dentro del proyecto Corriente Cultural de A Fundación en colaboración con la Xunta de Galicia y más de 35 municipios. Se trata de «la excepcional colección de imágenes sacadas en los años 20 por diferentes parajes de Galicia, retratando a nuestras gentes, costumbres y tradiciones, un legado etnográfico de valor incalculable» (A Fundación: 2020). Fue una de las más exitosas exposiciones organizadas en el ayuntamiento hasta el punto de que tuvieron que multiplicar por cuatro el número inicial de visitas guiadas programadas. Es una pequeña muestra de la enorme admiración que la obra de Ruth Anderson despierta en Galicia, donde tomó más 5000 imágenes. La recuperación y divulgación de su trabajo comenzó con las primeras exposiciones organizadas en la década de 1990s entre la Xunta de Galicia y la Hispanic Society of America. Por tanto, se puede decir que las fotografías de 
Ruth Anderson constituyen un elemento perceptiblemente fructífero en la reconstrucción de la memoria cultural gallega y las exploraciones y narraciones de su identidad.

La Hispanic Society, en colaboración con distintas instancias políticas y culturales españolas, como el Centro de Estudio de Castilla La Mancha(UCLM) o la Xunta de Galicia, ha llevado a cabo una importante labor de divulgación de su Colección de Fotografía y Grabados en nuestro país en los últimos veinte años en distintas exposiciones y catálogos. Esta presencia se ha multiplicado exponencialmente en Internet. Muchas de las imágenes de Ruth Anderson hoy en día circulan incesantemente por distintos espacios digitales de manera que se han convertido en parte de la memoria colectiva de aquella España de hace un siglo. Son el relato visual de una cultura popular, articulada por la negociación entre la calidad artística de la obra y el juego con la tradición y la nostalgia invocada en su obra. A la función de patrimonio documental que desempeñan las fotografías históricas, que directamente nos vinculan con aquella realidad presentada, se incorpora esta construcción digital de la cultura popular. Se producen por tanto nuevas formas de representación y de reivindicación de distintas configuraciones de identidades locales y regionales. Todo ello abre múltiples dimensiones conceptuales y contextuales en la comprensión de los significados culturales que plantea esta práctica representativa.

\section{La Colección Fotográfica de la Hispanic Society of America: retratos de la CULTURA ESPAÑOLA EN ESTADOS Unidos}

Como otros filántropos y coleccionistas de la Gilded Society, Archer Milton Hungtinton (1870-1955) fundó la Hispanic Society of America en la ciudad de Nueva York el 18 de mayo de 1904 como biblioteca, museo e institución educativa gratuita para promover el conocimiento y el estudio de la lengua y la cultura hispana. «Un museo [indicaba Huntington] que ha de abarcar las artes, incluyendo las artes decorativas, y las letras, ha de condensar el alma de España en contenidos, a través de obras de la mano y del espíritu. No ha de ser un montón de objetos acumulados al buen tuntún hasta que todo ello parezca una asamblea artística, los vestigios medio muertos de naciones entregadas a una orgía. Lo que quiero es ofrecer el compendio de una raza» (Naranjo Orovio, 2014: 125) Esta institución fue uno de los pilares de la consolidación de los estudios hispanos en Estados Unidos en el siglo XX. Se trata de una empresa cultural asombrosa fruto del esfuerzo y voluntad de un solo hombre, lo que lo convierte en un museo sumamente particular, perfecto reflejo de su visión y comprensión de España. Representaba un claro posicionamiento de oposición a lo que Kagan (2002) ha denominado «el paradigma Prescott», que enfatizaba la leyenda negra y la visión peyorativa de España en los Estados Unidos.

Huntington, millonario y filántropo, fue una reconocida figura de la alta sociedad neoyorkina y ha sido definido como un campeón de la promoción de las relaciones entre España y Estados Unidos (Codding, 2002). Único hijo de un magnate industrial, se decidió desde muy joven por el estudio y la filantropía (Fernández Lorenzo, 2018). La gran obra de su vida fue la creación de la Hispanic Society a la manera de otros coetáneos como J.P. Morgan o Frick. Su erudición, relaciones sociales, tanto en España como en Estados Unidos, y capacidad económica definieron no solo el ideario y los objetivos de la institución, sino su praxis a lo largo de toda su historia. La Hispanic es el empeño de un único hombre, y todos sus proyectos deben ser analizados a la luz del retrato de España y los propósitos que Huntington estableció en la adquisición y ordenación de la colección. 
Enormemente erudito tras su formación con tutores privados y viajes a Europa, el mito dice que durante su primer viaje a Londres en 1882 leyó la obra de George Borrow lo que inició su fascinación por nuestro país (Socias Batet, 2010). Esta pasión habría germinado en sus viajes al Sur estadounidense donde entró en contacto con el español, y fue reforzada por su acercamiento a los círculos de los primeros hispanistas norteamericanos (Remeseira, 2010). Su primer viaje a España tuvo lugar en 1892, descubriendo todo un nuevo mundo alejado de las visiones más turísticas. Comenzó así a cultivar su interés particular por la España más rural donde encontraba más fidedignamente su ideal romántico del auténtico país. La combinación de lo histórico y lo anecdótico cristalizó en un ideario conservador que regirá la Hispanic.

Ciertamente, Huntington pensaba que la España real estaba lejos de las ciudades y apartada de los estereotipos e imágenes más o menos turísticas. En su diario (véase Lenaghan, 2016) fue dejando constancia de su visión y modelo de comprensión de España. Admiraba los pueblos de las regiones rurales, que aún eran huella de una imagen real del pasado. Sus habitantes todavía mantenían las auténticas tradiciones, la esencia genuina de España puesto que esos hombres y mujeres que luchaban por la supervivencia encarnaban la integridad y la honestidad. Su interés no se limitaba solo al más conocido Sur del país, sino que consideraba que el Norte también tenía una tradición a reivindicar. Fue un apasionado de lo pintoresco, de cómo en cada región se podía apreciar un carácter especial y distintivo. Las tradiciones, los deportes, los vestuarios, las costumbres invocaban ese pasado en sus diferentes expresiones y especificidades.

En esta búsqueda coincidía con el objetivo de recopilar y preservar la supuesta pureza de una España primitiva de distintas instituciones culturales que promovían la cultura popular como el fundamento de la identidad nacional en la época:

...una imagen romántica del pueblo español, a la que antes los escritores y los pintores, como Sorolla, también habían contribuido, y que no estaba lejana de las ideas sobre la cultura tradicional que tenía Menéndez Pidal o la invención del tipismo como recurso económico que ya desde 1911 patrocinaba el Comisario Regio para el Turismo, el marqués de Vega-Inclán. Esas gentes de carácter, retratadas con el fondo de sus acusados paisajes y monumentales pueblos, vestidas con aquellos impresionantes trajes atávicos, configuraban una imagen del campesino español construida sobre el exotismo y la distancia cultural y, así, de algún modo paradójico, aparecían como un patrimonio culturalmente relevante para los europeístas, burgueses y modernos intelectuales de la JAE. Este retrato del pueblo ennoblecido por los fotógrafos constituía la raíz propia, la base diferencial de la cultura española sobre la que trabajar y en la que encontrar inspiración por parte de los humanistas, pero también la materia prima en la que había que labrar el futuro de una nueva nación sobre bases democráticas y de justicia social (Ortiz García, 2007: 135).

Con el mismo espíritu y vocación de rescate de esa cultura tradicional, Huntington también promovió en la Hispanic Society of America la creación de un archivo fotográfico español, para documentar las costumbres, la cultura y el arte españoles, y contribuir al desarrollo de la investigación. Consideraba la fotografía una eficaz herramienta de documentación y conocimiento, una forma de registro que complementaba las notas y diarios de campo (Lenaghan, 2016). Por ello en la colección primaba la naturalidad y el realismo de lo documentado sobre la calidad estética de las obras. Para organizar el archivo fotográfico adquirió un amplio número de obras de fotógrafos españoles o extranjeros que habían trabajado en el país. La colección comenzó con las propias 
fotografías tomadas por Huntington, a las que se añadieron las que había comprado o recibido por donación de distintos autores, como Laurent, Garzón, Linares Moreno o Hielscher. También se sumó la colección de la estadounidense Anna Christian, que había viajado a España en 1915 por recomendación de Sorolla, tras la exposición de su obra que se organizó en la institución en 1916. Igualmente, Hungtinton financió las expediciones del matrimonio Byne, entre 1915 y 1921 cuando cesó su relación con la Hispanic Society. Tras este desencuentro, Hungtinton envió a su propio equipo de investigadoras y recolectoras de material, entre las que podemos destacar a Ruth Matilda Anderson, Alice D. Atkinson y Frances Spalding.

Ciertamente, hay que subrayar que en la Hispanic Society of America solo trabajaban mujeres. No porque Huntington tuviera un punto de vista particularmente progresista o feminista, sino porque le parecían mucho más dóciles y permeables a su forma de trabajo, a la visión que encarnaba la institución. Después de algunas experiencias poco satisfactorias con investigadores independientes en la Hispanic Society of America, Huntington decidió emplear solo a jóvenes mujeres (Lenaghan, 2016). Prefería contratar personal que pudiese modelar y formar en los métodos y los principios con los que había diseñado y organizado la colección. Las tareas de estas mujeres no solo se desarrollaban como bibliotecarias, archiveras o conservadoras de las colecciones, sino que también fueron enviadas a España, tanto para profundizar en su formación para poder desempeñar correctamente sus tareas en los archivos, como en misión de trabajadoras de campo para contribuir a la ampliación de la colección, particularmente en lo que nos interesa, a través de la adquisición o realización de fotografías (Naranjo Orovio, 2014).

Siguiendo los rigurosos principios y exigencias de Huntington, las investigadoras de campo debían estudiar las lenguas y las culturas locales antes de viajar. Principalmente en la década de los años 20 del pasado siglo recorrieron España, así como otros países de Latinoamérica, y obtuvieron más de 15.000 fotografías archivadas hoy en el Departamento de Grabados y Fotografías, junto con la obra de los mencionados autores locales (Lenahan, 2007). De hecho, el encargo de Huntington era que comprasen aquellas fotografías ya disponibles, fundamentalmente arquitectura monumental o piezas artísticas, disponibles porque despertaban un interés más generalizado en el público, y se centrasen en fotografiar ellas mismas distintos aspectos de la vida cotidiana y las costumbres, que habían sido fotografiados de forma muy limitada. Por ello, tanto sus habilidades como hablantes de español, así como su conocimiento de la realidad local fueron enormemente útiles para el éxito de estas misiones en España.

Entre las trabajadoras enviadas a España, estaba Ruth Matilda Anderson que desarrolló un magnífico trabajo como fotógrafa de carácter etnográfico al servicio de Huntington. Fue la más prolífica de las investigadoras enviadas a nuestro país, además de publicar distintos libros con imágenes de su trabajo como Gallegan Provinces of Spain: Pontevedra and la Coruna; In the Lands of Extremadura: Ruth Mathilda Anderson's Photographs of Western Spain for the Hispanic Society; o Images in Procession: Testimonies to Spanish Faith. Paulatinamente, su interés se fue centrando en estudio de la indumentaria española, hasta que en 1954 fue nombrada Conservadora de Indumentaria de la Hispanic Society, cargo que desempeñó hasta su retiro (Lenaghan, 2016). El espectacular trabajo de Ruth Anderson está indisolublemente unido a la Hispanic como apunta Zamorano (2019:1) «El sentido y trascendencia de la obra de Ruth M. Anderson no podría entenderse sin la perspectiva de su vinculación a esta entidad durante toda su trayectoria profesional». 


\section{Ruth Matilda Anderson, unA ARTista CON VOCACiÓn DOCUMENTAL}

Ruth Matilda Anderson nació en Nebraska en 1893, hija de un fotógrafo especializado en retratos y paisajes con el que adquirió sus primeros conocimientos de la disciplina. Tras estudiar en la universidad estatal un grado como maestra musical, se trasladó a Nueva York donde se formó como fotógrafa en la Clarence H. White School for Photography, la primera escuela profesional de fotografía en Estados Unidos, que combinaba el rigor técnico que primaba los valores estéticos y artísticos con la creación documental (MONA: 2020). El trabajo de Ruth M. Anderson representa claramente esta manera de entender la fotografía como arte y testimonio. En 1921 comenzó a trabajar como Conservadora de Fotografía en la Hispanic Society of America, recomendada por el propio White (Espinosa, 2011).

La fotografía de Ruth Anderson se caracteriza por su capacidad de empatía con los protagonistas retratados, lo que tendría su origen según Lenaghan (2016) en sus raíces personales. Su infancia y adolescencia en una Nebraska pobre y poco mecanizada la habrían preparado para la España rural y vernácula que debía ilustrar. No juzgaba la falta de modernidad - o atraso como describirían otros viajeros - y se mostraba solidaria con las personas que fotografiaba al comprender la dureza de sus condiciones de vida. Esta habilidad personal se vería potenciada por el perfeccionamiento técnico, el conocimiento del país derivado de la formación en cultura hispana recibida en la Hispanic. La propia Ruth Anderson explicaba en Esbozo de un texto para un libro su adiestramiento en la institución alabando los métodos de formación de Huntington:

Durante tres años apasionantes estuve en la Hispanic realizando experimentos fotográficos, catalogando libros mediante las fotografías de las portadas, elaborando una lista de libros a partir de las fotografías de las fichas catalográficas, haciendo libros fotográficos y pequeñas monografías sobre objetos de la colección, fotografiando objetos de arte y trabajando con ayudantes sordas. Además de ganar experiencia en cuestiones técnicas, comencé a aprender cosas sobre un mundo que desconocía, el mundo de los asuntos importantes, de la erudición y de las letras por medio del contacto casi diario con un jefe que pertenecía a ese mundo y que lo podía describir con brillantez, con inagotable simpatía y con humor... Aprendí que el experimento era un experimento en educación: se estaba formando un personal de auténticos académicos (Anderson, 2016: 430).

Por tanto, Ruth Anderson no solo reconocía la calidad de la formación recibida, sino que mostraba su sintonía con el trabajo y las propuestas de Huntington, lo que la convertiría en el mejor instrumento para documentar y fotografiar su visión de España. Siguiendo una rigurosa disciplina de trabajo, Ruth Anderson no solo tomaba fotografías, sino que recopilaba información y documentaba su trabajo, lo que ha dado lugar a una extensa colección de diarios de campo que se conservan en los archivos de la Hispanic Society (Espinosa, 2011). Esta labor documental se vio facilitada por su competencia lingüística en español, e incluso en gallego. En Esbozo de un texto para un libro explica su capacitación idiomática:

...tenía alrededor de ocho semanas para prepararme y durante ese tiempo también estuve intentando prepararme para otros aspectos del trabajo. El año anterior había viajado por muchas ciudades de España y había comenzado a aprender la lengua. Podía preguntar bastantes cosas en castellano...Pero solo podía entender una parte muy pequeña de las amables y fluidas respuestas que este tipo de preguntas provocaban. Sin embargo, esta dificultad se resolvería en seguida por sí sola al practicar en España (Anderson, 2016: 432). 
Esta capacidad le permitía compartir tiempo y charlar con las personas que quería retratar, lo que dota a sus fotografías no solo de una enorme naturalidad puesto se aprecia la comodidad de sus protagonistas, sino también la habilidad de retratar el momento justo y la naturaleza de la acción documentada. De esta forma, Ruth Anderson se convirtió en un excelente practicante de una fotografía que podríamos clasificar como etnográfica.

Sus orígenes rurales, su formación musical y como fotógrafa, la competencia técnica, así como sus diligentes hábitos de trabajo y documentación la convirtieron en la perfecta retratista de la España que Huntington quería compendiar:

Las fotografías de Anderson reflejan la visión de Huntington sobre lo que constituía la verdadera España, concuerdan perfectamente con su planteamiento y contemplándolas, sólo cabe decir que el proyecto experimental de documentar fotográficamente nuestro país, salió mucho mejor de lo que ambos llegaran a imaginar (Museo Casa Cervantes).

\section{La etnografía Fotográfica de Ruth ANderson en España, Retrato al NATURAL de un IDEAL DE COTIDIANIDAD}

El primer viaje de Ruth Anderson a España tuvo lugar entre el 17 de marzo y el 3 de Julio de 1923 en compañía de Catherine Allyn, Anna Pursche, Mrs. Allyn y Mrs. Foraler. Con el objetivo de empaparse de la cultura local, perfeccionar su formación y recoger material español de Arte, Vida y Cultura recorrieron la geografía nacional durante más de tres meses y regresaron a Nueva York con 771 fotografías (véase Espinosa, 2011).

Después de este primer viaje, recibió el encargo de desplazarse a España durante un año para documentar fotográficamente la vida y las costumbres en Galicia. Como escribe en Esbozo de un texto para un libro «Me relegaron del personal. Después se determinó que debía ir a España a estar un año allí haciendo fotografías. Mi salario, cómodo y seguro, se había evaporado, y desde ese momento debería gastar conforme a los pagos por las fotografías de trajes, casas de labranza, iglesias, paisajes, carros, barcos, redes, arados, objetos de arte o escenas populares que pudiese realizar o comprar y remitir a la Hispanic» (Anderson, 2016: 430).

Quizá este tipo de contrato junto a la profesionalidad, rigor y la virtuosa implicación personal explican la enorme productividad de Ruth Anderson que llegó a tomar más de 14.000 fotografías. Desde ese momento, se convirtió en la principal documentalista fotográfica de nuestro país. Partió para España el 29 de julio de 1924 acompañada por su padre. Recorrieron Galicia y Asturias desde su llegada a Vigo hasta que regresaron el 28 de agosto de 1925. Apenas unos meses más tarde, repetiría periplo entre el 14 de noviembre de 1925 y el 31 de mayo de 1926, acompañada por otra fotógrafa de la Hispanic, Frances Spalding. Además de continuar su exploración por Galicia también cubrieron León. Regresaría nuevamente del 29 de diciembre de 1927 al 28 de abril del 1928 cuando documentó Castilla y Extremadura. Su último viaje de la década fue entre el 5 de octubre de 1929 y el 17 de noviembre de 1930 cuando fotografió no solo España, sobre todo Andalucía, sino también Portugal y Marruecos. Después de la guerra civil española y la segunda guerra mundial entre 1948 y 1949, Anderson y Spalding regresaron a España y Portugal después de viajar a Brasil. Todavía regresaría en distintos viajes cortos, hasta su último periplo a nuestro país en 1967 (Espinosa: 2016).

El itinerario de todos estos viajes estaba condicionado por los temas que debía investigar y documentar. Siguiendo las instrucciones y principios de Huntington no le interesaban ni los aspectos más urbanos con calles trazadas por automóviles y fábricas, 
ni los elementos artísticos, ya reconocidos por la Academia por lo que se centra en las regiones rurales y remotas. Su propósito era documentar una realidad no solo menos reconocida sino también más infrecuente de oficios tradicionales, reuniones populares y formas de vida cotidiana de la mayoría de la población rural. Quería de manera naturalista retratar personas y lugares representativos de lo que creía una España auténtica:

Lo que nos interesa resaltar aquí de la obra dedicada a España por R. M. Anderson es su objetivo de rescate documental —usando el método que entonces aparecía como el más objetivo, fiable y, en suma, científico: la fotografía - de unas formas de vida, unos tipos humanos, un color local que en España (y concretamente en algunas de sus regiones) aparecían como milagrosamente preservados y no irrevocablemente muertos, todavía no sustituidos del todo por el desarrollo económico, la técnica y el maquinismo (Ortiz García, 2007: 135).

Sus extensos diarios de campo, conservados en los archivos de la Hispanic Society dan cuenta de sus preguntas e investigaciones. Además, se conservan también el diario que su padre escribió de su primer viaje y otras notas y cartas de la propia Ruth Anderson. En la correspondencia se ven claramente las exigencias e instrucciones de Huntington que demanda entre otras cosas localizar geográficamente cada fotografía completando el nombre de la aldea o lugar con la situación respecto a los pueblos o ciudades más próximos. Ruth Anderson iba enviando fotografías en la medida en que las revelaba y el presidente de la Hispanic contestaba orientando el trabajo hacia los intereses y carencias que percibía en la colección. Cada fotografía se documenta con una ficha en la que se indica la localización, la fecha, la hora y distintas anotaciones relevantes sobre las personas retratadas, en lo que se ha definido como una etnografía fotográfica, una memoria visual. (Lenaghan, 2016)

La propia Ruth Anderson expresa en su correspondencia con Huntington esta vocación antropológica de su trabajo: «...para una comprensión real del sujeto no se puede sustituir el método que hemos tenido el privilegio de emplear, viajando de pueblo en pueblo de la región, hacienda nuestras propias fotografías y reuniendo la información con la ayuda de la gente que había confeccionado y vestido la indumentaria» (citada en Espinosa, 2011: 249. Traducción propia).

Ciertamente, las fotografías de Ruth Anderson tienen un marcado carácter etnográfico al documentar detalladamente la sociedad que retrata. De hecho, tal como en la Antropología se hace trabajo de campo, Ruth Anderson primero se informa y aprende en Nueva York, donde revisa toda la literatura disponible y estudia mapas y geografía para trazar itinerarios. Esta documentación previa al campo en contacto con Huntington es extensa. Igualmente elabora itinerarios de viaje, que denomina Outlines, detallando cómo debe realizar el trabajo y todo lo que debe ser cubierto (véase Espinosa, 2011: 249250). Ya en el terreno, observa, convive y conversa con los protagonistas de sus retratos, se informa de procedimientos y condiciones de vida, de prácticas y expectativas. En el diario de su padre se puede leer su impaciencia por el aburrimiento que le provocan estas largas conversaciones que no entiende porque a diferencia de su hija no habla español ni gallego (Anderson, 2016). Incluso los curas se convierten en informantes privilegiados como haría años más tarde Carmelo Lisón Tolosana en su etnografía de Galicia: «Los sacerdotes siguen siendo nuestros mejores amigos. Todavía ocupan el antiguo rol de recopilar tradiciones y conservar sus vestigios») (Carta de Ruth Anderson dirigida a su madre. 5-1-1925 citada en Espinosa, 2011: 257). En 1950 en la publicación Spanish 
Costume: Extremadura agradece la colaboración a sus interlocutores «La autora agradece profundamente la amabilidad de ciudadanos y aldeanos, de paisanos y pastores, y de las mujeres que instantáneamente dejaban lo que estuvieran haciendo para ayudar a una extraña» (citada en Espinosa, 2011: 264. Traducción propia).

Y no solo se documenta, observa, registra y dialoga con sus informantes, sino que, en su trabajo fotográfico, además de la preferencia por lo rural y humilde, también retrata iglesias y casas nobles, mercados, personas desempeñando distintos trabajos o prácticas artesanas, actividades cotidianas, fiestas, romerías... Toda la realidad que vive con un empeño que casi podríamos definir como holístico. Sirva como ejemplo el detalle con el que explora los distintos aspectos del abastecimiento de la vida rural a partir de la elaboración de pan. En el análisis de sus imágenes podemos aprender cómo se conforma hasta el mínimo detalle todo el procedimiento. Encontramos fotografías que exponen los campos de cereal, las tareas agrícolas, distintos tipos de molinos empleados en la producción de harina, las tareas de amasado y cocción, los hornos y la leña necesaria para su encendido y funcionamiento, las marcas de cada zona o familia, la venta del producto final... Todas las tareas de hombres y mujeres, los instrumentos y materiales necesarios para la elaboración de pan, los circuitos de consumo y comercialización, las diferencias socioeconómicas, explicitadas en los tipos de hornos o molinos, las jerarquías, la dimensión de organización territorial derivada de los circuitos de venta... son algunas de las múltiples dimensiones que podemos aprender del estudio de los retratos de Ruth Anderson.

La complicidad que Ruth Anderson establecía a través de esta forma de trabajo se transmite en la naturalidad que sus fotografías. De esta manera resulta razonable conectar su obra con el naturalismo propio de buena parte de la fotografía estadounidense de las décadas de los veinte y treinta del pasado siglo. Desde el realismo social de Dorothea Lange o Margaret Bourke-White, al retrato de las comunidades rurales americanas de Doris Ulmann o Laura Gilpin. Todas ellas como Ruth Anderson y otra de las fotógrafas de la Hispanic Society Alice D. Atkinson, fueron discípulas de la Clarence H. White School for Photography. La formación recibida en la escuela puede trazarse en los trabajos fotográficos que desarrollarían estas últimas para la Hispanic Society y las primeras en Estados Unidos. El retrato simultáneamente naturalista y estético de los desfavorecidos sociales caracteriza sus obras, aunque con principios ideológicos subyacentes tan diferenciados como la propuesta romántica folklorizante de Huntington o la postura del relato social concienciado de la serie encargada por la Farm Security Administration del gobierno Roosevelt para documentar y definir los valores americanos durante la Gran Depresión.

White, que junto a Alfred Stieglitz fundó la agrupación Photo-Secession, se fue desplazando hacia el modernismo, siempre abogando por la introducción de lo artístico y estético en la obra fotográfica (Yochelson, 1983). La fotografía era una de las bellas artes, pero también arte práctico y aplicado. En su escuela se enseñaba por tanto esta cualidad artística que se combinaba con el compromiso social, marcado por los principios artísticos definidos por Dow y el empoderamiento educativo de Jonh Dewey (Yochelson, 2014). La aproximación práctica a la enseñanza de White enfatizaba los aspectos técnicos como composición, iluminación o contraste, el trabajo con líneas, masas y espacios en escenarios cotidianos. Promovía el diseño y la composición de la imagen como ejercicios prácticos del buen artista. Por ello, animaba a presentar los sujetos fotografiados en su ambiente natural y próximo, reforzando la necesidad de resolver los problemas técnicos derivados de este ejercicio en el mundo real, fuera del estudio, con la experiencia 
personal. Todas estas enseñanzas serían enormemente útiles en los ejercicios de realismo y naturalismo de sus estudiantes.

Además, como profesor del Departamento de arte del Teachers College de la Universidad de Columbia, seguía los principios de promover la educación como herramienta de movilidad social tanto para la clase trabajadora como para las mujeres, que constituyeron un número importante de sus estudiantes. Durante su etapa como profesor el número de alumnas en su escuela era superior al de hombres. Su promoción de las artistas mujeres se unía al más fácil acceso de las mismas a la fotografía por ser considerada todavía un arte menor y reciente. Y sus estudiantes demostrarían más tarde una mayor afinidad, interés o sensibilidad también por tratar temas de género en sus retratos (McEuen, 2000).

Siguiendo estas enseñanzas, el trabajo de Ruth Anderson se caracteriza por la suma de lo artístico y lo documental que podemos rastrear en la utilización de escenarios naturales, y en unos retratos que parecen captar momentos vitales más que posados. También se aprecia la predisposición social en la representación del trabajo y las condiciones de vida de las personas corrientes, así como en el interés por mujeres y niños como personas más vulnerables. En la dirección apuntada, en la mirada documental y respetuosa de Ruth Anderson destacan particularmente los retratos femeninos, que en la época eran ordinariamente ignoradas o invisibilizadas. Medina Quintana (2016) ha estudiado como la fotografía de Ruth Anderson documenta la actividad laboral femenina en las primeras décadas del siglo XX. Las mujeres están retratadas en el ejercicio de oficios remunerados como el comercio o la hostelería, las tareas agrícolas y ganaderas, la venta de productos agropecuarios, los trabajos relacionados con el mar como rederas o mariscadoras, o los trabajos textiles. La representación se amplía a espacios de sociabilidad femenina como lavaderos o mercados.

No está claro si Ruth Anderson ejercitaba un claro posicionamiento feminista, aunque no podemos olvidar su membresía en la Ciencia Cristiana, cuya relación con la denominada en la época cuestión de la mujer todavía es objeto de análisis feminista en la investigación actual (Voorhees, 2012). Cierto es que su propia condición femenina la hacía más consciente de la presencia de las mujeres, normalmente invisibles para la mirada masculina que acepta el modelo de los hombres como universales (Scott, 1999). Y su trabajo, entre las muchas lecturas que abre como elemento de la cultura documental, sí facilita claramente un análisis contemporáneo con perspectiva de género.

Efectivamente, analizamos como las mujeres son mostradas por Ruth Anderson como sujetos y agentes sociales, en roles activos como trabajadoras, gestoras de capital y competentes en la toma de decisiones. Son representaciones visuales que significan y alteran la percepción de los estereotipos de género al caracterizar la participación femenina tanto en los denominados trabajos domésticos o reproductivos como en los productivos. Se produce, por tanto, una ruptura de la imagen generalizada de lo femenino y lo masculino. Igualmente, podemos apreciar la construcción generizada del espacio y las estrategias femeninas de la ocupación de los espacios masculinos, por ejemplo, en las tabernas. En las fotografías de Ruth Anderson vemos como esos lugares vedados para el ocio femenino se abrían a las mujeres en su condición de trabajadoras.

En otro orden de ideas y satisfaciendo la visión de Huntington de la cultura tradicional, Ruth Anderson se empeña en la búsqueda de la particularidad y la especificidad de la vida española. Este interés tomará forma en el registro de la vida festiva y ritual, de los bailes y los cantos. En particular la fascinación por el tipismo y la originalidad queda reflejada en la documentación de la indumentaria, como prueba la utilización de la 
entonces moderna fotografía en color para retratar mejor los matices, las tonalidades y las texturas. En sus palabras: «Mi interés principal eran los trajes [tachado «y mi principal problema sería probablemente encontrar trajes que fotografiar y obtener autorización para eso»], no el vestido en sí mismo, sino la manera de vivir y lo accesorios cotidianos en las provincias que íbamos a visitar» (citado en Espinosa, 2011: 432). Por tanto, siguiendo con la vocación etnográfica estos elementos de cultura material se emplean como herramientas de conocimiento de una forma de vida y no solo en su dimensión estática de objetos artísticos. Es más, en su condición de elementos utilizados fundamentalmente en el ámbito festivo y ritual enlazan directamente con esa preservación de la tradición frente a la modernidad cada vez más acusada de la vida cotidiana.

Así pues, en su opinión los rituales y los bailes son campos donde la vida tradicional mantiene una mayor vigencia:

Después del almuerzo decae un poco la animación, pero cuando la gaita comienza de nuevo a penetrar la charla con suspiros y silbidos secundados por las vibraciones del tambor, los jóvenes solteros se levantan para buscar un espacio nivelado para sus bailes. De estos, la muñeira es el más natural; es una pantomima del cortejo, la chica moviéndose despacio en un punto, manteniendo los ojos bajos mirando al suelo, jugando con las castañuelas en la mano baja, el hombre bailando a su alrededor con unos pasos y gestos extravagantes (citado en Espinosa, 2011: 597. Traducción propia).

Nos adentramos, pues, en el espacio complejo de la preservación patrimonial enlazada con la invención de la tradición provocada por la fosilización de lo folklórico.

No obstante, ella misma es consciente del cambio y la modernización de una sociedad que se desvanece todavía preservada en sus trajes, vestidos y adornos. Estaba interesada en documentar un mundo que todavía veía en la realidad cotidiana, aunque cada vez más difuminado y apropiado en el revival urbano. De esta forma, el estudio de esta evolución también la hace consciente de las dinámicas tradicionalistas y del folklorismo implícito en su recuperación por parte de las élites urbanas:

La chica del pueblo de hoy se considera vestida para un festival si tiene un pañuelo de seda fresca y una buena blusa y falda con, por supuesto, un paraguas proteger su finura. Los trajes de Aldeana y Gaiteiro son vestidos mayoritariamente por señoritas y señoritos de la ciudad en sus actuaciones en las sociedades corales que se han organizado para conservar la música nativa. Los uniformes de la sociedad coral se hacen con una fidelidad aproximada al estilo tradicional, la costura es a máquina, los materiales de fabricación comercial, y con poca atención al detalle (citado en Espinosa, 2011: 237. Traducción propia).

Y esta consciencia crítica la haría en su último viaje mostrarse mordaz con los usos de la Sección Femenina por su falta de respeto y la carencia de una investigación rigurosa al servicio de los usos políticos de la tradición «Sus trajes, dijo la jefa de la Sección, no se basaban en prendas reales ni siquiera en una fotografía de un traje, sino en las descripciones de las ancianas que todavía recuerdan algo» (citado en Espinosa, 2011: 501. Traducción propia). Creía que los trajes y las prácticas desplegadas por las falangistas eran invenciones, artificialmente forzadas.

En otras palabras, en el trabajo de Ruth Anderson podemos encontrar apuntes de las propias paradojas de la conservación al explorar la búsqueda de la autenticidad y una reflexión crítica sobre los usos políticos de la tradición. De hecho, sus fotografías 
no traslucen una intencionalidad exotizadora ni se recrea en una peculiaridad forzada para producir una falsificación folklorizante. Ruth Anderson no parece caer en los trucos de otras coetáneas como Doris Ulmann, cuya obra en los Apalaches ha sido criticada por presentar protagonistas caracterizados con atuendos anticuados o acompañados de objetos de la época preindustrial para representar una ruralidad ideal (Brown, 2001). No obstante, hay que considerar que la propia España ya resultaba suficientemente exótica para la mirada estadounidense, sobre todo, en la óptica romantizada y conservadora de Huntington que de alguna manera nos enlaza con la reinvención del folklore en el siglo XX y el proceloso análisis de la autenticidad como un constructo cultural. (Handler, 1986)

En este sentido, tampoco se debe obviar que las fotografías congelan ilusoriamente un proceso dinámico y no deben ser tomadas más que un reflejo puntual de la realidad. La condición retórica de la fotografía crea una falsa impresión para los espectadores como apunta Bagés Villanueva (2004: 249) «Toda imagen fotográfica es metonímica. La relación entre representación y realidad tiene un fondo metonímico, debido a que el 'todo' está representado por elementos que tienen con este una relación directa. La fotografía fragmenta la realidad, toma una parte, hace una selección que tendrá una función metonímica para el observador. Sin ser consciente de las relaciones y entramados que al parecer son evidentes.»

Por tanto, sin confundir los códigos por los que la fotografía y la realidad aparentan tener la misma naturaleza, por lo que la imagen sería realidad y no representación, las aparentemente espontáneas y verdaderas imágenes deben ser entendidas como un ejercicio construido tanto en el propósito de la autora como en la apreciación de los espectadores. Tanto la autoría fotográfica como la mirada etnográfica siempre deben ser analizadas en su intencionalidad sin dejarnos engañar por la aparente inmediatez de lo representado, sobre todo, cuando la naturalidad impregna el trabajo como ocurre en la obra de Ruth Anderson.

\section{Redescubriendo a Ruth ANDERSON: LeCturas Digitales}

Las fotografías de Ruth Anderson inundan nuestros dispositivos digitales cuando se teclea cualquier variación de «fotografías antiguas de España». La enorme calidad de las imágenes, su sosegada belleza y la empatía y cercanía que transmiten sus protagonistas le han otorgado un merecido protagonismo en nuestro relato digital del pasado. Las fotografías de Ruth Anderson en este crisol infinito contribuyen a la producción de un territorio imaginado e imaginario, con un elemento personal implícito en la recreación de la cultura popular. Su potencial se incrementa porque se suman dos elementos que comparten su condición de herramientas democráticas y no jerarquizadas, dado que aparentemente son accesibles y al alcance de todos, lo digital y la fotografía.

Como recurso digital que se modela y expresa en la experiencia personal, esta cultura popular se fragmenta y multiplica. Cada persona que publica o comenta una foto de Ruth Anderson añade su relato y se van construyendo narrativas con múltiples facetas. De esta manera, se utilizan los retratos para reivindicar el día de la mujer trabajadora, comentar la dureza de las condiciones de vida pasada, denunciar el trabajo infantil, asombrarse ante las dificultades de transporte en aquella época, celebrar la belleza de una calle, evocar el recuerdo melancólico del pasado, de una vida que se presenta como más sencilla y espontánea, se propone el estudio detallado de un motivo de vestuario para una reproducción de los trajes... En cada interacción se teje una tupida red que se enreda y desenvuelve en cada filtro de búsqueda, con cada elemento añadido, como los comentarios, los recuerdos, la música o las críticas. 
Al abordar el análisis de los usos de las fotografías de Ruth Anderson según el planteamiento teórico de la praxis (Ortner, 2006), que contempla como todo producto cultural cobra sentido en un tiempo y un espacio determinado, se evitan formulaciones esencialistas. En consecuencia, el proceso de actualización de la práctica cultural digital debe ser estudiado en las prácticas, creencias, hábitos y narrativas desplegados para comprender los significados, las reformulaciones y las apropiaciones que hacemos de estos elementos. En los usos efectuados y los comentarios formulados a Ruth Anderson el conjunto comprende entre innumerables ejemplos desde la búsqueda del pasado familiar en el reconocimiento de un protagonista a la asociación a un espacio o un escenario, así como el recuerdo de trabajos o formas de vida pasada. Los comentarios van creando esos vínculos personales y sociales, componiendo una comunidad heterogénea e ilimitable. Las fotografías de Ruth Anderson se convierten, como dice Edwards (2012) en un objeto social de agencia, que facilita el diálogo en la aproximación de la experiencia digital, al avivar la conversación y las narrativas sociales. Si las fotografías son herramientas de memoria, comunicación y conversación, la digitalización permite una lectura multigeneracional y la enunciación desde múltiples posiciones.

Y no podemos disociar esta acción personal del discurso y la narrativa social, que también se difundirá en el espacio digital, aunque sea de forma inconsciente. Conjuntamente a la dimensión personal e íntima, el componente emocional funciona como elemento de exploración de las identidades culturales y reafirmación de las identidades locales. Como bien patrimonial, las fotografías se utilizan en la consolidación cultural y como instrumento para recalibrar las representaciones comunitarias. En palabras de Rafael Villena y Lucía Crespo Jiménez (2007: 14):

La fotografía adquiere ese carácter patrimonial por su capacidad para registrar, para con-tener en un soporte físico información sobre la sociedad, la cultura, la política, el arte o la vida cotidiana de un momento dado. Tiene, pues, la virtud de rememorar un periodo histórico concreto, o al menos un pedazo del mismo. En ese momento, se convierte en testigo de la historia y ello le confiere un valor importante para su análisis. De ahí que la fotografía pueda constituir por sí misma parte de la identidad cultural de una sociedad y sea necesaria su conservación.

En esta negociación de las perspectivas culturales sobre España, el pasado y la historia es revelador comparar como el conocimiento de Ruth Anderson en nuestro país es más amplio en Galicia, Asturias y Castilla-La Mancha, donde su obra ha sido objeto de numerosas exposiciones que construyen un relato del pasado. La obra fotográfica de Ruth Anderson contribuye a la creación de comunidad en el discurso de la conciencia colectiva como símbolo comunitario. En el caso de Galicia, el gobierno de la Xunta presidido por Manuel Fraga en la década de los noventa formuló un relato de país con un punto folklórico y populista, que encontró una eficaz herramienta en la difusión de esa imagen romantizada y afectiva de las fotografías de Ruth Anderson como patrimonio histórico. No solo apelaban directamente al recuerdo y el corazón de gallegas y gallegos, sino que estaban dotadas de la hegemonía de la verdad por la condición metonímica de la fotografía revisada anteriormente. En las exposiciones programadas en los últimos años se mantiene ese discurso del que también se ha beneficiado A Fundación, obra social de Abanca, anteriormente Caixa Galicia. Su programación cultural refuerza la 
simbiosis del banco con Galicia, como institución al servicio y representativa de la comunidad.

Estas prácticas identitarias se multiplican exponencialmente en la comunicación multilateral de la divulgación digital. Cada interacción en la red va diluyendo el contexto de producción tanto de las fotografías como de las iniciativas de exposición contemporáneas. Se olvida que toda fuente documental debe ser necesariamente contextualizada porque ha pasado a ser patrimonio de todos en nuestro ejercicio digital, simultáneamente compartido e individual. Por tanto, la narrativa es cada vez más eficaz al obviar que no hay relato aséptico ni objetivo ni imparcial. No obstante, no se trata de un ejercicio excluyente o exclusivo porque la pluralidad del medio también permite la articulación de otros discursos y otras redes.

En definitiva, en la interpretación de la digitalización de la cultura popular configurada a través de las fotografías de Ruth Anderson se debe incidir en la comprensión $\mathrm{y}$ exposición de todas las narrativas y percepciones de esa conciencia histórica e identitaria. La aplicabilidad de Ruth Anderson es poderosa y la espectacular calidad de sus fotografías alienta la revitalización de la cultura popular con múltiples significados en ejercicios virtuales que conforman la reproducción de identidades personales y sociales.

\section{REFLEXIONES FINALES}

El legado de Ruth Anderson ha sido extraordinario, tanto por su aplicado esfuerzo que produjo un corpus monumental como por la excepcional belleza y calidad de sus fotografías. Su obra es comparable tanto por las características técnicas como por los temas y enfoques seleccionados a otras mujeres fotógrafas compatriotas y coetáneas, como Dorothea Lange o Doris Ulmann, pero mucho más desconocida en su país de origen. Probablemente, el hecho de que desarrollase su trabajo en España y siempre bajo el auspicio e instrucciones de la Hispanic Society, casi solapada con la institución, haya ensombrecido su popularidad al otro lado del Atlántico.

Su obra desempeña un papel imprescindible en nuestro conocimiento actual del pasado español y en la contemporánea conciencia histórica y patrimonial. Desde un comprometido trabajo de campo abrazó la visión romántica de Huntington en busca de la autenticidad, pero consiguió evitar una folklorización exotizante a través de la empatía con sus sujetos. En esta línea se puede encuadrar su sensibilidad por dar visibilidad a las mujeres o presentar oficios y tareas en un relato contextualizado. De esta manera sus imágenes transmiten una preferencia por lo natural sobre la estética, cuando lo cierto es que, en razón de su esmerada calidad técnica, el público lego no es consciente de la elegante composición y el discurso construido por su mirada.

La exploración de este discurso fotográfico conduce a la reflexión sobre la práctica contemporánea sobre el pasado derivada de la exposición tanto física como digital de su trabajo. Como patrimonio documental, el legado de Anderson contribuye a la configuración de las identidades culturales, así como la conformación de vínculos en la representación de la comunidad. La enfatización de diferentes narrativas y percepciones de la conciencia histórica son apoyadas diestramente en la emoción. En la dimensión virtual del fenómeno los usuarios, los artistas, los programadores culturales, los políticos... producen simultáneamente diferentes lecturas que responden a distintos intereses y las diferentes condiciones económicas, políticas, sociales en los que se desenvuelve cada individuo y colectivo. Además, se produce un ejercicio de retroalimentación constante 
que multiplica su efecto a la vez que en muchas ocasiones diluye la conciencia de autoría o intencionalidad. Sobre todo, al partir de unas fotografías que fortalecen el relato de la naturalidad y la metonimia con la realidad en los objetos representados. Esta luz crítica explicita la construcción del relato imaginado de las fotografías de Anderson como expresiones de la memoria y de la imagen de la cultura popular española.

\section{BiBLIOGRAFÍA}

Anderson, Ruth Matilda (2016): «Esbozo de un texto para un libro», en Una mirada de antaño. Fotografías de Ruth Matilda Anderson en Galicia (2 ${ }^{\mathrm{a}}$ Edición), A Coruña, A Fundación, pp. 428-437.

Anderson, Alfred Theodore (2016): «Cartas y diarios», en Una mirada de antaño. Fotografias de Ruth Matilda Anderson en Galicia (2 ${ }^{\text {a }}$ Edición), A Coruña, A Fundación, pp. 437-441.

BAgÉs VillanedA, Juanita (2004): «Estructuras metafóricas en la imagen fotográfica», en Segundas Jornadas Imagen, Cultura y Tecnología, María Pilar Amador Carretero, Jesús Robledano Arillo y María del Rosario Ruiz Franco (eds.), Getafe, IGTMU, pp. 241-254.

Brown, Elspeth (2001): «Seeing America: Women Photographers between the Wars», The Journal of American History; Oxford, 87, 4, pp. 1547. DOI: https://doi. org/10.2307/2674852

Codding, Mitchell A. (2002): «Archer Milton Huntington, the Champion of Spain in America», en Richard Kagan (ed.) Spain and the United States: The Origins of American Hispanism, Urbana, University of Illinois Press, pp. 142-170.

Díaz Zamorano, Asunción (2019): «Fotografía y emoción en la mirada de Ruth Matilda Anderson», en Crónica Global del Pensamiento, 24 de febrero.

EDWARDS, Elizabeth (2012): "Objects of affect: photography beyond the image», Annual Review of Anthropology, 41, pp. 221-34. DOI: https://doi.org/10.1146/annurevanthro-092611-145708

Espinosa Fernández, Noemí (2011): La fotografía en los fondos de la Hispanic Society of America: Ruth Matilda Anderson Tesis Doctoral. Repositorio de la Universidad de Castilla-La Mancha. URL: < https://www.educacion.gob.es/teseo/ imprimirFicheroTesis.do?idFichero $=5 \% 2 \mathrm{~F} \% 2 \mathrm{BE} 5 \mathrm{ZfrDlc} \% 3 \mathrm{D}>$.

Espinosa Fernández, Noemí (2016): «Los viajes de estudio y expediciones en la Hispanic Society of America», en El Greco en su IV Centenario: patrimonio hispánico y diálogo intercultural, María Esther Almarcha Núñez-Herrador, Palma MartínezBurgos García y María Elena Sainz Magaña (eds.), Ediciones de la Universidad de Castilla-La Mancha, pp. 609-629.

Fernández Lorenzo, Patricia (2018) Archer Milton Huntington. Madrid, Marcial Pons

Handler, Richard (1986) «Authenticity», Anthropology Today, vol. 2, 1, pp. 2-4. DOI: https://doi.org/10.2307/3032899

Kagan, Richard (Ed.) (2002): Spain and the United States: The Origins of American Hispanism, Urbana, University of Illinois Press.

Museo Casa de Cervantes: La Casa de Cervantes a través del objetivo de Ruth Matilda Anderson URL: <http://www.culturaydeporte.gob.es/museocasacervantes/ actividades/exposiciones-temporales/expo-anderson.html $>$. 
LenAGHAN, Patrick (2007): «La visión de Archer M. Huntington y las fotografías de CastillaLa Mancha en The Hispanic Society», en Viaje de ida y vuelta. Fotografías de Castilla-La Mancha en The Hispanic Society of América, Ciudad Real, Empresa Pública Don Quijote de La Mancha S. A., pp. 56-66.

Lenaghan, Patrick (2016): «Las campañas de Anderson. Elaborando una crónica de Galicia», en Una mirada de antaño. Fotografias de Ruth Matilda Anderson en Galicia, A Coruña, A Fundación, pp. 15-43.

McEuen, Melissa A. (2000): Seeing America: Women Photographers between the Wars, Lexington, The University Press of Kentucky.

Medina Quintana, Silvia (2017): «El trabajo rural femenino en la fotografía de Ruth Matilda Anderson: un recurso didáctico para Educación Primaria», Digilec: revista internacional de lenguas y culturas, vol. 4, 2017, pp. 69-88. DOI: https:// doi.org/10.17979/digilec.2017.4.0.1868

Mona, Museum of Nebraska Art files: Biography of Ruth Matilda Anderson URL: <https:// mona.unk.edu/mona/ruth-matilda-anderson $>$.

Naranjo Orovio, Carmen (2014) «Al hilo de la cultura: España y Estados Unidos, 19001940», en Escuela Diplomática (ed.) Legado español en los Estados Unidos, Ministerio de Asuntos Exteriores y de Cooperación, pp. 121-146

Ortiz GarcíA, Carmen (2007): «Raíces hispánicas y culturas americanas. Folkloristas de Norteamérica en el Centro de Estudios Históricos», en Revista de Indias, vol. 67, 239, pp. 125-172. <http://hdl.handle.net/10261/8599>

Ortner, Sherry (2006): Anthropology and Social Theory: Culture, Power, and the Acting Subject, Durham, Duke University Press. DOI: https://doi. org/10.1215/9780822388456

RemeseiRA, Claudio Iván (2010): «A Splendid Outsider: Archer Milton Huntington and the Hispanic Heritage in the United States», en Hispanic New York. A Sourcebook, Claudio Iván Remeseira (ed.), New York, Columbia University Press, pp. 443456.

Scotт, Joan Wallach (1999): Gender and the Politics of History, Nueva York, Columbia University Press.

Socias BATET, Inmaculada (2010): La Correspondencia entre Isidre Bonsoms Sicart y Archer Milton Huntington. El Coleccionismo de Libros Antiguos y Objetos de Arte, Barcelona, Real Academia de las Buenas Letras.

Villenna, Rafael y CRespo Jiménez, Lucía (2007): «Fotografía y Patrimonio», en Introducción al II Encuentro de Fotografía en Castilla-La Mancha, Cuenca, Servicio de Publicaciones de la UCLM, pp. 13-19.

Voorhees, Amy B. (2012): «Mary Baker Eddy, the Woman Question, and Christian Salvation. Finding a Consistent Connection by Broadening the Boundaries of Feminist Scholarship», Journal of Feminist Studies in Religion, 28.2, pp. 5-25. DOI: https://doi.org/10.2979/jfemistudreli.28.2.5

Yochelson, Bonnie (1983): «Clarence H. White Reconsidered: An Alternative to the Modernist Aesthetic of Straight Photography». 9 (4), pp. 24-44. URL: $<$ https://repository.upenn.edu/svc/vol9/iss4/3>. DOI: https://doi.org/10.1111/ j.2326-8492.1983.tb00095.x

Yochelson, Bonnie (2014): «The Clarence H. White School of Photography» en Mitra Abbaspour, Lee Ann Daffner, and Maria Morris Hambourg, (eds.) Object:Photo. Modern Photographs: The Thomas Walther Collection 1909-1949. An Online 
Project of The Museum of Modern Art. New York: The Museum of Modern Art, URL: $<$ http://www.moma.org/interactives/objectphoto/assets/essays/Yochelson. pdf $>$.

Fecha de recepción: 9 de marzo de 2020

Fecha de aceptación: 27 de junio de 2020

$$
9
$$

